Chapman University

Chapman University Digital Commons

ESI Working Papers

Economic Science Institute

2010

\title{
Do Analysts Tell the Truth? Do Shareholders Listen? An Experimental Study of Analysts' Forecasts and Shareholder Reaction
}

Timothy W. Shields

Chapman University, shields@chapman.edu

Follow this and additional works at: http://digitalcommons.chapman.edu/esi_working_papers

\section{Recommended Citation}

Shields, T.W. (2010). Do analysts tell the truth? Do shareholders listen? An experimental study of analysts' forecasts and shareholder reaction. ESI Working Paper 10-05. Retrieved from http://digitalcommons.chapman.edu/esi_working_papers/126

This Article is brought to you for free and open access by the Economic Science Institute at Chapman University Digital Commons. It has been accepted for inclusion in ESI Working Papers by an authorized administrator of Chapman University Digital Commons. For more information, please contactlaughtin@chapman.edu. 


\title{
Do Analysts Tell the Truth? Do Shareholders Listen? An Experimental Study of Analysts' Forecasts and Shareholder Reaction
}

\author{
Comments \\ Working Paper 10-05
}




\title{
Do Analysts Tell the Truth? Do Shareholders Listen? An Experimental Study of Analysts' Forecasts and Shareholder Reaction
}

\author{
Timothy Shields * \\ Chapman University \\ The George L. Argyros School of Business and Economics
}

21 January 2010

\begin{abstract}
This work experimentally examines forecasting and trading behavior. Subjects play the role of both analyst and shareholder over the course of experiments consisting of a series of repeated games with or absent conflicts of interest. In a stylized trading setting, I test whether standard equilibrium, normative behavior, or limited strategic reasoning best predicts behavior. In the presence of conflicts of interest a substantial proportion of subjects' behavior appears non-skeptical in the role of shareholder, though the same subject is deceptive in the role of analyst. Absent conflicts of interest, subjects behavior in the role of shareholder is nearer a best response to the same subject's behavior as analyst. The results are consistent with limited strategic reasoning and suggest that simply disclosing conflicts of interest does not evoke skepticism of forecasting, nor does the elimination of conflicts of interest in itself induce honesty.
\end{abstract}

Keywords: conflicts of interest, truth-telling, cheap talk, communication game, experiment

Data Availability: experimental data available from author on request

*Telephone: 714.289.2092; E-mail address: shields@chapman.edu 


\section{Introduction}

Sell-side analysts are compensated, at least in part, by brokerage commissions. The U.S. Securities and Exchange Commission cites brokerage commissions as a potential conflict of interest, stating, "[An] analyst report can help firms make money indirectly by generating more purchases and sales of covered securities - which, in turn, result in additional brokerage commissions [Securities and Exchange Commission, 2008]. This suggests that forecasts that move the market are possibly attractive to analysts.

In this work, I experimentally examine behavior in an institutional market setting. In this setting, an analyst with private value-relevant information issues a forecast to shareholders. The shareholders can then elect to trade; if there is trade, the analyst is paid a commission in two conflict-of-interest experiments. In two other experiments, the analyst is paid a flat fee if the shareholders trade or not.

The incentive created by brokerage commissions is an example of the economic tensions modeled in communication games, sometimes also called cheap talk games [Crawford and Sobel, 1982]. In analytical models of communication games, a sender with information transmits a message to a receiver, who then takes an action that affects the payoffs of both the sender and the receiver. If there are conflicts of interest in that the sender would prefer the receiver to take an action other than the action that is best for the receiver, then not all information can be credibly communicated. In equilibrium, the sender will not adopt a truth-telling strategy and the receiver will be skeptical. As a result, the messages will at best be partially informative and at worst completely uninformative. Several experimental studies examining communication games show that senders of information do adopt deceptive strategies when the interests of the receiver and sender diverge [Blume et al., 1998; Dickhaut et al., 1995]. However, while subjects exhibit a willingness to deceive others in communication games, a phenomenon of overcommunication is documented: senders reveal more information than analytical theory predicts, and receivers rely more on the sent information [Cai and Wang, 2006; Sánchez-Pagés and Vorsatz, 2007; Wang et al., 2009].

Experimental studies examining communication games posit that the overcommunication can be explained by the existence of types of subjects. Both Sánchez-Pagés and Vorsatz [2007] and Hurkens and Kartik [2009] posit that observed behavior could be explained by the existence of two types of subjects: those who behave akin to equilibrium prediction and maximize payoffs and those who subscribe to social norms of honesty. While these studies examine behavior in one-shot communication games, where the sender and receiver are grouped together one time, the presence of honest types may prevent the repeated game from reducing to a series of one-shot games and allows for reputation building as a sender seeking to maximize profits may elect to mimic an honest type.

A related but alternative explanation of the overcommunication phenomenon is that subjects fail to sufficiently reason. Rather than the possibly endless iterations needed to arrive at equilibrium (I know that you that I know that you know that I know...), a nonequilibrium theory of levels of reasoning assumes that subjects seek to maximize payoffs but fail to reason sufficiently, yielding a static and possibly erroneous belief of others' strategies. In a 
communication game, this theory would predict some subjects who are deceptive if playing the role of sender but at the same time non-skeptical in the role of receiver.

In this work, I examine behavior in an institutional market setting to distinguish behavior from the prior experiments of communication games conducted in a context-neutral setting. I have the analyst and shareholders play a repeated game for a set number of rounds. After the set, subjects are regrouped and roles are reassigned. In this way, I can measure a subject's behavior both in the role of analyst and in the role of shareholder. Within the stylized setting, I ask what best explains overall subject behavior: standard equilibrium prediction, the existence of types following social norms, or models of limited reasoning?

Other accounting experiments examine behavior of subjects who disclose (akin to analysts) to other subjects who interpret the disclosure (akin to shareholders) in the presence of conflicts of interest [Dickhaut et al., 2003; Hobson and Kachelmeier, 2005; King and Wallin, 1991]. They find that senders have a propensity to disclose strategically to maximize payoffs and that receivers exhibit some skepticism. In this work, I too find that overall, analysts behave deceptively in the conflict-of-interest experiments; however, I find that overall, shareholders are not sufficiently skeptical. Most enlighteningly, I find many examples of subjects who are deceptive in the role of analyst but non-skeptical in the role of shareholder. As such, a subject's behavior in the role of shareholder is inconsistent with his own behavior in the role of analyst. The experimental behavior is consistent with limited levels of reasoning.

When examining experiments in which the conflicts of interest are removed, where the analyst has no reason to lie but also no reason to tell the truth, I find that analysts are not significantly more likely to forecast their private information, although their behavior appears more erratic than in the experiments with conflicts of interest. Shareholders appear economically better off in the absence of conflicts of interest. Subjects behavior in the role of shareholder is more consistent with their behavior in the role of analyst. Together, the findings suggest that behavior in the market setting is not coherent with standard equilibrium predictions, but it does appear that the majority of subjects act in their own best interest rather than following ethical dilemma, analogous to the findings of Rankin et al. [2008] examining disclosure in a budget setting. Instead, behavior appears consistent with models of allowing for limited strategic reasoning. The implication is that simply removing conflicts of interest may not result in a behavior following social norms.

Section 2 describes the experimental setting, followed by predictions based on standard equilibrium, the existence of types, and levels of strategic reasoning. Section 3 describes the experimental procedures. Section 4 presents the results, and section 5 concludes.

\section{The Setting and Predictions}

I start by describing the repeated game used in all four experiments. First, I describe a setting with conflicts of interest between the analyst and shareholders. In this setting, the analyst can only earn commissions if the two shareholders trade. Thereafter I discuss an alternative game absent the conflicts of interest. Then I describe standard equilibrium behavior and discuss similar but competing theories of behavior and denote the resulting 
hypotheses. Throughout the work, I will refer to the analyst as "she" and the shareholder as "he." All prices, costs, and payoffs are expressed in the experimental monetary unit lira.

\subsection{The Experimental Game}

I design an experimental setting to capture elements in the analyst and shareholder relationship. A single analyst is paired with two shareholders. To induce trade one shareholder must be willing to sell and the other willing to buy. The payoffs are constructed to provide potential gains to trade. Each shareholder acts simultaneously as both seller and buyer to mitigate promotion of directed behavior. The game is repeated a finite number of times to provide the analyst an opportunity to develop a reputation.

\subsubsection{Conflict-of-Interest Experiments}

An analyst and two shareholders play a repeated game. Each three-person base game consists of the following stages:

1. Two shareholders are endowed with a unit of a financial asset, and an analyst is given a private signal of the state of nature.

2. The analyst releases her forecast of the state of nature to shareholders.

3. A market opens such that one shareholder can sell his asset to the other. The analyst earns a commission that is contingent on the shareholders agreeing to trade.

4. The asset is liquidated. The liquidation amounts are a function of the state of nature and the asset owner.

To understand the fundamental tension in the game, I start by describing the fourth stage. In the last stage of the game, the state of nature is drawn from the set $\{A, B, C, D\}$, and shares are liquidated. The ex-ante value of each share is identical. The shareholders have different payoffs from the liquidated shares, a proxy for shareholders having different preferences or facing different tax rates. While the difference in payoffs is symmetrical, the payoffs are asymmetrical and provide potential gains to trade. The payoffs and differences in payoffs are shown in Table 1a.

In stage 1 , the analyst receives a private signal regarding the state of nature. The private signal, $s \in\{\tilde{A}, \tilde{B}, \tilde{C}, \tilde{D}\}$, is uniformly distributed. There is a $90 \%$ probability that the realized state will equal the private signal. The signal has limited support in that the realized state will be an element of the set $\{A, B\}$ when the signal is either $\tilde{A}$ or $\tilde{B}$, and the realized state will be an element of the set $\{C, D\}$ when the signal is either $\tilde{C}$ or $\tilde{D}$ (see Table 1b). The signal structure, state, and signal distributions are common knowledge, whereas the realization of the analyst's signal is private to the analyst.

In the second stage, the analyst releases a message, $f \in\{\hat{A}, \hat{B}, \hat{C}, \hat{D}\}$. If the realization of the private signal, $s$, is an element of $\{\tilde{A}, \tilde{B}\}$, the analyst can release a forecast of either $\hat{A}$ or $\hat{B}$. Likewise, if $s \in\{\tilde{C}, \tilde{D}\}$, the analyst can release a forecast of either $\hat{C}$ or $\hat{D}$. The reporting 
technology is common knowledge, so after the forecast is released, shareholders know that the state is in either $\{A, B\}$ or $\{C, D\}$. The setting with moving support allows the most parsimonious structure to investigate behavior in the presence of conflicts of interest.

In the third stage, a market opens and the shareholders can trade. If there is trade, a shareholder buys the other's share at a transfer price $P$, selected from a menu of prices, and when there is trade, the buyer pays trading $\operatorname{costs} \lambda$. Shareholder 1 is restricted to buying or retaining his share when the state is $A$ or $B$ and to selling or retaining this share when the state is $C$ or $D$. A symmetric restriction is placed on shareholder 2 .

In the first of two experiments with conflicts of interest, labeled "low-cost," $\lambda$ is only the 13-lira commission paid to the analyst. In the second experiment, labeled "high-cost," $\lambda$ is 21 lira and includes 9 lira in deadweight costs in addition to the 13-lira commission. Each shareholder retains his endowment if there is no trade; if there is no trade, the analyst earns nothing. The trading costs exceed the difference in payoffs in states $B$ and $C$. The gains to trading jointly available to shareholders are shown in Table 1c.

Insert Table 1 here

Four trading prices are presented, as follows: P1, 7 lira; P2, 23 lira; P3, 83 lira; and P4, 91 lira. If the shareholders believe that the analyst is forecasting honestly, then P1 and $\mathrm{P} 4$ are the feasible prices when the forecast is $\hat{A}$ and $\hat{D}$, respectively. P1 and P4 are parameterized to split the expected gains to trade equally between the two shareholders, given that the analyst reports honestly and shareholders trade for forecasts $\hat{A}$ and $\hat{D}$. In the low-cost experiment, if the two shareholders believe that the analyst is reporting deceptively, then P2 and P3 are the feasible prices when the forecast is an element of $\{\hat{A}, \hat{B}\}$ or $\{\hat{C}, \hat{D}\}$, respectively. P2 and P3 are parameterized to split the expected gains to trade equally between shareholders given that the analyst reports deceptively and shareholders always trade. In the high-cost experiment, no price is feasible when both shareholders believe that the analyst is deceptively forecasting. Ex post payoffs for all trading scenarios are shown in Tables $3 \mathrm{a}$ and $3 \mathrm{~b}$.

\subsubsection{No Conflict-of-Interest Experiments}

The game differs in two additional experiments. As in the conflict-of-interest experiments, an analyst and two shareholders play a repeated three-stage game. However, the analyst earns a fixed payoff independent of whether shareholders trade. Consequently, the analyst has no economic reason not to reveal her private signal.

In the first of two experiments absent conflicts of interest, labeled "no-budget," all payoff amounts mirror the low-cost experiment; that is, the analyst and shareholder payoffs and costs are the same, but the contingent structure of analyst payoffs is removed. The shareholder's ex post payoffs are shown in Table 2a. The analyst's private signal is governed by Table 2c. Restrictions on what report can be sent and whether the shareholder can act as buyer and seller are maintained. The trading costs are 13 lira, and the analyst's fixed payoff is 13 lira. 
Though this experiment is comparable to the low-cost experiment, the setting violates budget balancing. Analysts are not paid out of realized gains to trade. As such, the parties benefiting from the analyst's private information are not directly funding the analyst. As such, the setting is politically awkward and would likely prove difficult to implement. From a social engineering perspective, it might be more palatable if those who benefited from private information paid for it.

In a second experiment lacking conflicts of interest, labeled "no-commission," I alter payoffs such that shareholders indirectly fund the analyst's payoff. The analyst is paid 4 lira every game, mirroring the average analyst payoff in the high-cost experiment (13 lira commission times the likelihood of trade). Shareholder 1's ex post payoff decreases 4 lira in states $A$ and $B$, and shareholder 2's ex post payoff decreases 4 lira in states $C$ and $D$ (see Table $2 \mathrm{~b}$ ). The changes in payoffs are analogous to an institution taxing and redistributing resources. Trading costs are 9 lira and paid by the buyer if there is trade.

While the gross payoffs differ for shareholders, the gains to trade are identical in both noconflict-of-interest experiments as in the low-cost experiment. In the no-budget experiment, a trading cost of 13 lira is subtracted from the difference in payoffs shown in Table 2a to arrive at gains to trading available to shareholders. In the no-commission experiment, the trading cost of 9 lira is subtracted from the difference in payoffs shown in Table $2 \mathrm{~b}$ to arrive at the same gains to trading, both shown in Table $2 \mathrm{~d}$.

Insert Table 2 here

Prices P1 through P4 are set to the same values as in the conflict-of-interest experiments. P1 and P4 are feasible if the shareholders belief that the analyst reports honestly, and P2 and P3 are feasible when the shareholder believes that the analyst reports deceptively. Ex post payoffs for all trading scenarios are shown in Tables $3 \mathrm{c}$ and $3 \mathrm{~d}$.

Insert Table 3 here

\subsection{Predictions}

In this section I discuss the standard equilibrium for all experiments. This discussion illustrates the effects of conflicts of interest and thus provides insight into alternative theories of behavior. Research examining similar communication games finds that senders (analysts) reveal more information than predicted by standard equilibrium theory and that receivers (shareholders) rely more on the sent information than predicted [Cai and Wang, 2006; Sánchez-Pagés and Vorsatz, 2007; Wang et al., 2009]. Additionally research in the area of financial markets has provided empirical evidence that financial analysts exaggerate recommendations. Michaely and Womack [1999] attribute this documented bias to conflicts of interest between the analysts and investors, citing both brokerage commissions and the investment banking business as possible sources. Both Malmendier and Shanthikumar [2007] and Franco et al. [2007] find evidence of differences in the reaction of investors, suggesting that some investors, the smaller investors, are misled by deceptive recommendations despite 
the disclosure of conflicts of interest. Given the experimental and archival findings, I look to alternative behavioral arguments from experimental economics and psychology.

The next set of predictions is constructed assuming that agents are heterogeneous or have a belief of population heterogeneity. Some agents follow socially normative behavior, whereas others seek to maximize their profits yielding predictions of behavior based on types. The last set of predictions assumes that agents are self-interested but do not iterate indefinitely in assessing best responses to others, but instead reason up to some number of steps. As such, these predictions differ from equilibrium as agents do reason sufficiently to arrive at equilibrium. This yields predictions based on various levels of reasoning.

\subsubsection{Equilibrium Predictions}

The equilibrium is constructed assuming that both the analyst and the shareholder are sequentially rational. Sequential rationality requires that the analyst's actions and beliefs be optimal and correct, respectively, given the shareholder's actions and beliefs.

\section{Equilibrium Predictions Given Conflicts of Interest}

Due to the inherent conflicts of interest created by trade-based commission payments, analysts adopt deceptive forecasting strategies, but shareholders are never duped as shareholders anticipate deception and all forecasts are interpreted with skepticism. Within this equilibrium scenario, though information is lost, shareholders are not deceived.

The standard equilibrium is constructed via backward induction. Start with the last period and imagine, to the contrary, that the analyst reveals her private signal via the forecast. In other words, the analyst adopts honest forecasting. In this case, the difference between the shareholders expected values are shown in Table 4a; the difference exceeds trading costs $\lambda$ (of 13 or 21 lira) only in states $A$ and $D$. Consequently, there is trade $50 \%$ of the time, when the forecast is $\hat{A}$ or $\hat{D}$, at prices $\mathrm{P} 1$ and $\mathrm{P} 4$, respectively.

Given the contingent nature of the commission, an analyst would desire the shareholders to trade. As such, the analyst does not want to credibly communicate that the state is likely $B$ or $C$. It follows that the forecasting analyst cannot reveal her private information in all cases, and she adopts a deceptive forecasting strategy. Anticipating deception, shareholders are skeptical of the forecast. As a result, the information content of the forecast is limited to the reporting restrictions; a forecast of $\hat{A}$ or $\hat{B}$ only conveys that the state is either $A$ or $B$ with equal likelihood and not $C$ or $D$. Conversely, a forecast of $\hat{C}$ or $\hat{D}$ only conveys that the state is either $C$ or $D$ and not $A$ or $B$. We are at the equilibrium prediction: analysts destroy information content and shareholders are skeptical of forecasts. If shareholders fail to anticipate deception and continue to trade at prices $\mathrm{P} 1$ and $\mathrm{P} 4$, then on average trade benefits shareholder 1 at the expense of shareholder 2. Shareholder 2 will sell at P1 while the average value of 20 lira is higher. Likewise, shareholder 2 will buy at P4 and incur trading costs but the average value of 100 lira is lower.

\section{Insert Table 4 here}

Skeptical shareholders hold the expected payoff values shown in Table 4b. In the low-cost experiment, the difference between the two shareholders' expected values (20 lira) exceeds 
trading costs of 13 lira. Risk-neutral shareholders will trade for all forecasts released at prices P2 for forecasts $\hat{A}$ or $\hat{B}$ and at prices P3 for forecasts $\hat{C}$ or $\hat{D}$. In the high-cost experiment where trading costs are 21 lira (13 lira commission plus 9 lira in deadweight costs), trading costs exceed the difference between expected values of appropriately skeptical shareholders. As such, shareholders will not trade.

Hypothesis 1. In the presence of conflicts of interest, subjects will be deceptive in the role of analyst and skeptical in the role of shareholder.

\section{Equilibrium Absent Conflicts of Interest}

The conflicts of interest are eliminated when the analyst's payoff is independent of the shareholders trade. Interests are not aligned, but there is no economic conflict between analyst and shareholders. Absent invoking a tie-breaking rule, there is no unique equilibrium prediction. The analyst may reveal her private signal, or she may elect to destroy information. If the shareholders believe that the analyst is forecasting honestly, their expected payoffs are shown in Table 4a. As such, trade occurs half the time at prices P1 or P4, when the analyst releases a forecast of $\hat{A}$ or $\hat{D}$, respectively. However, if the shareholders believe that the analyst is forecasting deceptively, their expected payoffs are shown in Table 4b, and trade occurs all the time at prices P2 and P3.

\subsubsection{Type-Based Predictions}

Experimental research examining communication games posits that the overcommunication can be explained by the existence of types of subjects. Sánchez-Pagés and Vorsatz [2007] experimentally examines a communication game, followed by a punishment stage. The experiment differs from this work as the subjects are paired together for one round, there are conflicts of interest between the the pair in all states of nature, and most importantly, the communication game is followed by a punishment costly phase where the receiver can reduce both parties payoffs to zero after seeing the realized state. Hurkens and Kartik [2009] examines Gneezy [2005] communication experiment where a subjects are paired and play one round and only the sender (akin to analyst) is told the ex-post payoffs. Both Sánchez-Pagés and Vorsatz [2007] and Hurkens and Kartik [2009] posit that the experimental results can be explained by two types of subjects: those who behave akin to equilibrium prediction and maximize payoffs and those who subscribe to social norms of honesty. This supposition may lead to behavior described by H. L. Mencken: "It is hard to believe that a man is telling the truth when you know that you would lie if you were in his place." Following this logic, subjects will act consistent with their own actions. If a subject is deceptive in the role of analyst, that subject is skeptical of analysts in the role of shareholder. If the subject is honest in the role of analyst, that subject is non-skeptical of analysts in the role of shareholder.

Hypothesis 2. Subjects will demonstrate behavior in the role of shareholder that is consistent with their own behavior in the role of analyst.

Sobel [1985] analyzes a finitely repeated information transmission game in which the sender, analogous to the analyst in this work, has preferences that are aligned with the 
receiver or that differ; that is, the sender may be one of two types. The uncertainty as to the sender's type prevents the repeated game from reducing to a series of one-shot games as providing honest information in the setting increases the sender's reputation but comes at a cost to the strategic type, who cannot mislead the receiver too quickly, thus revealing her type, but nonetheless will eventually attempt to deceive the receiver. The prediction is similar to the analytical research of Kreps and Wilson [1982] and Kreps et al. [1982], where agents are predicted to develop a reputation for being one type. Experimental research examining Centipede games [McKelvey and Palfrey, 1992], repeated lending games [Camerer and Weigelt, 1998], and repeated trust games [Dickhaut et al., 2008] provides evidence that some subjects attempt to develop a reputation for being a certain type.

Imagine that some fraction of analysts is honest, characterized as analysts who send truthful messages in all rounds of the repeated game. Shareholders have a prior belief of this fraction. Other analysts use this fact to deceive potentially skeptical shareholders in a repeated game. A strategic analyst might elect to mimic the honest type in potentially all but the last round of a repeated game as revealing herself as deceptive would trigger shareholder skepticism and thus no commissions in future rounds. As such, the anticipation of detection can temper deceptive forecasting as shareholders will be skeptical of an analyst caught using a deceptive strategy. The consequences of skepticism are a function of trading costs. If costs are large enough, as in the high-cost experiment, then skeptical shareholders cannot agree on a price and do not trade. If trading costs are small enough, as in the low-cost experiment, then skeptical shareholders can expect to capture gains trading despite deceptive forecasting. The opportunity to develop a reputation yields the following predictions.

Hypothesis 3. In the presence of a conflict of interest, analysts will initially adopt honest strategies and switch to deceptive strategies over a set of repeated one-shot games.

Hypothesis 4. Analyst behavior will be more honest in the high-cost than in the low-cost experiment as the analyst has an incentive to develop a reputation for being honest.

Hypothesis 5. Shareholders will become skeptical after witnessing deception.

\subsubsection{Levels of Strategic Reasoning}

Rubinstein [2006] examines thousands of unpaid responses to a version of the Traveler's Dilemma laid out by Basu [1994] and finds evidence of some subjects playing naïvely and other subjects responding as if others play naïvely. This structured heterogeneity is captured in models of strategic reasoning, capturing the idea that humans exhibit several distinct modes of behavior. Predictions based on differing levels of strategic reasoning are constructed on a nonstrategic base-level strategy. Each subsequent level of the hierarchy is a type defined as the best response, assuming that other players use a lower level of strategic reasoning. Experiment tests of models based on limited reasoning often outpredict the predictions derived in equilibrium models [Camerer et al., 2004; Nagel, 1995; Stahl and Wilson, 1994].

To illustrate, I use a guessing game from Nagel [1995] in which each player is asked to choose a number from 0 to 100 . The winner of the game is the player who chooses a number 
that is one-half the mean of all other players' choices. The prize is given to the winner, and all others receive nothing. If there is a tie, the prize is split equally between winners. The predicted Nash equilibrium is that all players choose zero. Using the levels of reasoning hierarchy, define the level-0 nonstrategic type as choosing uniformly over 0 to 100 . Then the level-1 type's best response is to choose 25 (one-half of 50). The level-2-type best response is to choose 12.5, and so on. Nagel [1995] examines the experimental results of the guessing game and finds subjects' responses between level 1 and level 2 . This finding is replicated by Ho et al. [1998], who examine a broader assortment of guessing games.

Examining communication games, Crawford [2003] cites early experimental evidence [Blume et al., 1998] and argues that the system of types should be anchored on the honest sender who preserves information content and the non-skeptical receiver who believes the message has information content. In this work, I also anchor my hierarchy on honest forecasting and non-skeptical trading. In the role of analyst, the nonstrategic type literally reveals private information in the released forecast. In the role of shareholder, the nonstrategic type garners information out of the forecast released.

Consider the presence of conflicts of interest between the analyst and shareholder. The subsequent level-1 type is a best response to others being honest and non-skeptical. As a result, the level-l type is deceptive as an analyst, attempting to mislead shareholders. However, the level-1 type is non-skeptical as a shareholder as level-0 types are honest as analysts. Consequently, the level-2 type is also deceptive as an analyst, attempting to mislead level-1 shareholders. As a shareholder, the level-2 type is skeptical as the level-1 types are deceptive as analysts. The actions of subsequent types are identical to level-2 and correspond to equilibrium predictions: analysts are deceptive and shareholders are skeptical. This hierarchy yields a unique prediction: a level-1 type that appears rational in the role of analyst but irrational in the role of shareholder. While this prediction appears at odds with the intuition inherent in the Mencken quote, the prediction mirrors the experimental findings of Cain et al. [2005]. The authors find that in the presence of a disclosed conflict of interest, senders tend to strategically bias their messages, and receivers generally do not sufficiently discount advice from senders.

Prominent experimental researchers suggest that these nonequilibrium models predict behavior in new or novel situations, and eventually, equilibrium behavior will emerge. As such, it is argued that the hierarchical model does not supplant standard equilibrium predictions but can be seen as a path to equilibrium. It is an open question as to whether subjects' behavior will be predicted by higher levels as this repeated game progresses. For example, Nagel finds limited reasoning even in repeated games. Other research examining deception and conflicts of interest does not find that subjects recognize deception sufficiently despite evidence of deception [Einhorn and Hogarth, 1978; Wilson and Brekke, 1994].

Given the phenomenon of overcommunication found in experimental strategic transmission games, I conjecture that there will be some proportion of the population that behaves as level-0. This conjecture, coined with the aforementioned experimental findings that overall behavior was explained by level-1 to level-2 thinking, suggests that there will some proportion of each of the aforementioned levels observed in experiments with a conflict of interest. 
As such, while subjects' behavior is heterogeneous, overall, analysts will behave deceptively, but shareholders will behave trustingly.

Hypothesis 6. In the presence of conflicts of interest, analysts will tend to be deceptive and shareholders will tend to be non-skeptical.

Now consider the absence of conflicts of interest between the analyst and shareholder. The subsequent level-1 prediction is a best response to the other being honest and nonskeptical. As before, the level-1 type is non-skeptical as a shareholder as level-0 types are honest as analysts. However, her actions as analyst are irrelevant to her payoff. Though she has no reason not to tell the truth, she also has no reason to tell the truth. Thus either being honest or not are both best responses. By the same argument, as a shareholder, the level-2 type can either be honest or not in the role of analyst. As a shareholder, the level-2 type is characterized as skeptical as his ex ante perception of the level-1 analyst is that she will play randomly.

\section{Insert Table 5 here}

Within this framework, level-1 behavior, characterized as a best response to level-0 behavior, may be observationally indistinguishable from level-0 behavior if the level-1 analyst elects to be honest. Additionally, in the absence of conflicts of interest, level-2 behavior may be honest in the role of analyst but skeptical in the role of shareholder: a combination of behavior excluded in the presence of conflicts of interest.

Examining 'hide-and-seek' games, Crawford and Iriberri [2007] consider that defining alternative behavior for the level-0 type may to alternate hierarchical models and/or distribution of types. By similar argument, the salience of the level-0 behavior might lead to a different proportion of types. Assuming that proportions of each level are relatively the same as in the experiments with conflicts of interest, I should see relatively more honest analyst behavior and equivalent non-skeptical behavior compared to the experiments with conflicts of interest. What if disclosure of conflicts of interest invokes images of normative or professional behavior in the eyes of shareholders, as suggested by Cain et al. [2005]? If so, then in the conflict-of-interest experiments, subject behavior is explained by an anchoring on the level-0 type. When removing the conflict of interest, this anchoring weakens and strategic reasoning increases, leading to a higher proportion using level-2 reasoning. A higher proportion predicts more honest analyst behavior but at the same time more skeptical shareholder behavior. The conjecture that higher levels will predict behavior in the no-conflicts-of-interest experiment yields the following prediction.

Hypothesis 7. In the absence of conflicts of interest, analysts will tend to be honest, and shareholders will tend to be skeptical.

\section{Experimental Methods}

The Centre for Interuniversity Research and Analysis of Organizations [2009, hereinafter CIRANO] ran experimental sessions in Montreal, Canada. Subjects are recruited by CIRANO 
using recruitment software [Greiner, 2004] from a standard subject pool consisting mainly of university students. Subjects remain anonymous to the author. Each session consisted of 12 subjects and no subject participated in more than one session.

Subjects interact with each other anonymously over a local computer network. The experiment is programmed and run using z-Tree software specifically designed for economic experiments [Fischbacher, 2007]. The computers are placed in such a way that all subjects can only view their own computer screens. Each experiment lasted approximately two hours, and the sequence is summarized subsequently. In all experiments, subjects are told the structure of the sender's private information, the forecasting mechanism, trading costs, and all potential payoffs for all roles. As such, subjects are aware of the presence, or absence, of conflicts of interest between analysts and shareholders. An ex ante quiz confirms that subjects understand the information structures, payoffs, and forecasting and trading mechanisms.

\subsection{Experimental Sequence}

The experimental sequence proceeds as follows:

1. An experimenter reads the instructions aloud while each subject follows along with his or her own copy of the instructions (see supplementary materials for example of instructions). The instructions explain the experimental procedures, information structures, and payoffs used in the experiment. While going over the instructions, the experiment asks subjects to write down their answers to several questions to ensure that they understand the experiment. Subjects' answers remain confidential. The experimenter reviews the correct answers. After and while the instructions are read, subjects are prompted to ask the experimenter if they have any questions regarding the experimental procedures.

2. Each subject is randomly and anonymously grouped into an economy with two other subjects. The identities of members within the economy are not revealed to any subject. An analyst is randomly selected within each economy, and others are assigned the role of shareholder, each owning a stock that pays a dividend.

3. The analyst inputs her reporting strategy for each possible value of her private signal. Meanwhile, the shareholders enter their trading strategies for each possible value of the analyst's forecast. Each subject has one minute to enter his or her decision. If the analyst fails to enter a decision, the computer uses her last input decision, or, if in the first round of the set, randomly determines the reporting strategy. If the analyst fails to make a decision, no commission is paid regardless of trade. ${ }^{1}$ If the shareholder fails to enter a decision, the computer assigns a strategy of no trade, and the shareholder keeps his endowment.

\footnotetext{
${ }^{1}$ No subject playing the role of analyst failed to enter her decision within this time frame. This rule is in place in all experiments.
} 
4. Using the input strategies, the computer draws ten realizations of the analyst's private signal and nature for each economy. The feedback is private to the three grouped subjects within the economy. A summary screen shows subjects the feedback, including their own payoff, of the ten realizations.

5. The preceding two steps constitute a round. Each economy of three subjects plays together for eight rounds.

6. Subjects are regrouped into new economies, as described earlier. Subjects are notified of the regrouping and acknowledge by clicking with a mouse.

7. Each subject is paid a ten Canadian dollar participation fee and the payoffs of ten randomly drawn realizations from the 64 rounds. One Canadian dollar is paid for every 15 lira earned. The average pay per subject is 37 Canadian dollars.

8. Each subject signs and dates a payment receipt form and receives payment.

\subsection{Grouping, Rounds, and Sets}

Within each experiment, an economy is defined as a grouping of one analyst and two shareholders. During each round, all subjects within the economy play the base game. The economy remains intact for a set of eight rounds. The economies are private from another as the results from one economy do not affect payoffs in other economies, and the information within an economy is not available to subjects outside the economy. After a set of eight rounds, subjects are regrouped and roles are reassigned. The repeated interaction enables a platform for reputation building and revised beliefs of others strategies. Reassigning roles enables examination of a subject's behavior in one role versus behavior in another.

\subsection{Capturing Subjects Choices}

I use the strategy method for eliciting choices from subjects. Following this method, subjects state contingent choices for every decision node they may face. This differs from a game in which a subject makes a decision at realized nodes. Comparisons of the strategy and realized node methods reported little difference in subject choices [Brandts and Charness, 2000; Cason and Mui, 1998; Oxoby and McLeish, 2004]. Subjects who play the role of analyst enter their reporting strategy before seeing a realization of the private signal; that is, for all possible values of the private signal, the analyst makes a binary choice: to reveal her signal truthfully or not (see Figures 1 through 3 in the supplementary materials for captures of the input screen). Meanwhile, subjects playing the role of shareholder enter their trading decisions, electing to buy, sell, or hold for each possible forecast value.

\subsection{Providing Feedback}

After subjects enter their decisions, the computer draws a realization of the state and private signal. Using the reporting strategy input by the analyst and realization, the computer 
determines the analyst's forecast from her input strategy. Using the shareholders' input trading strategies, the computer determines if there is trade for the released forecast. If the shareholders agree to trade at both the high and low price (high bid and low ask), then the lower price is used.

If the ask exceeds the bid or either shareholder 1 or shareholder 2 elects not to trade, the shareholders keep their endowed shares. Using the state and agreed on price, the computer determines the shareholders' and analyst's payoffs. The computer draws ten such realizations and reports the feedback in a summary table (see Figure 4 in the supplementary materials). The summary table included all realizations for all rounds played to date within the economy. This provides a rich history so that subjects can revise beliefs on others' strategies. Using the summary report, a subject can partially infer other subjects' strategies used in prior rounds of the current set. The shareholders' trading strategies are explicitly displayed for all forecasts released, but the analyst's strategy can only be inferred from the number of times the forecast released is not identical to the realized state. Knowing the analyst's signal structure, shareholders can in theory calculate the posterior likelihood that the analyst used an honest or deceptive forecasting strategy. Overall, if there is more than one mismatch of the forecast and realized state, it was more likely that the analyst used a deceptive forecasting strategy than an honest one.

\section{Results}

I begin with construction-dependent variables measuring subject behavior in the role of analyst and in the role of shareholder. These variables, measuring compliance with equilibrium predictions of deception and skepticism, are averaged over each subject in each experiment. The average subject behavior allows for tests of hypotheses based on equilibrium, the existence of types, and levels of strategic reasoning.

\subsection{Behavior Classification}

In every set, the subject is randomly assigned one of three roles. As such, not all subjects play each role the same number of times. Indeed, in one experiment, a subject never played the role of analyst. All other subjects played both roles, resulting in at least 8 choices in the role of analyst and 16 choices in the role of shareholder.

For each round, subjects' choices are classified into one of two types. The elicited forecasting choice is classified as honest or deceptive, and the elicited trading choice is classified as skeptical or non-skeptical.

\subsubsection{Analyst Choice Classification}

Each round, analysts choices are classified as either honest or deceptive, as follows:

Honest The analyst reveals her private signal in the message, forecasting $\hat{A}$ when the signal is $\tilde{A}, \hat{B}$ when the signal is $\tilde{B}$, and so forth. 
Deceptive The analyst does not choose to reveal her private signal for all possible values, destroying information.

Of the analysts' input choices classified as deceptive, in the conflict-of-interest experiments, nearly $60 \%$ elected to exaggerate a moderate signal of $\tilde{B}$ or $\tilde{C}$ and forecast $\hat{A}$ or $\hat{D}$ accordingly, and fewer than $10 \%$ were invertible, forecasting $\hat{B}$ when seeing $A, \hat{A}$ when seeing $B$, and so forth. In no-conflict-of-interest experiments, only about $26 \%$ elected to exaggerate a moderate signal of $\tilde{B}$ or $\tilde{C}$ and forecast $\hat{A}$ or $\hat{D}$ accordingly, and nearly $25 \%$ were invertible, forecasting $\hat{B}$ when seeing $\tilde{A}, \hat{A}$ when seeing $\tilde{B}$, and so forth.

\subsubsection{Shareholder Choice Classification}

A skeptical shareholder, anticipating deceptive forecasting, would recognize that there is limited information content in the analyst's forecast. For example, a forecast of $\hat{A}$ or $\hat{B}$ would be informationally equivalent, informing the shareholder that the state could not be $C$ or $D$. Each round, the shareholder choice is classified as either skeptical or non-skeptical, defined as follows:

Skeptical The shareholder inputs one bid/ask for both forecasts $\hat{A}$ and $\hat{B}$ and another bid/ask for both forecasts $\hat{C}$ and $\hat{D}$. This includes a shareholder electing not to trade for every forecast.

Non-skeptical The shareholder does not input a skeptical trading choice, but instead inputs bids/asks as if there is information content in the forecast.

The later classification does not require that bids/asks are monotonic in the forecast. However, only four observations of the 1,170 choices classified as non-skeptical had a higher bid/ask for $\hat{B}$ than for $\hat{A}$ and a higher bid/ask for $\hat{C}$ than for $\hat{D}$. Fewer than $10 \%$ had a higher bid/ask for $\hat{B}$ than for $\hat{A}$ or a higher bid/ask for $\hat{C}$ than for $\hat{D}$. Accordingly, this coding captures subjects who tried to extract information content from the forecast. The frequencies of each subjects elicited choices are shown in Table 6.

Insert Table 6 here

\subsubsection{Performance in Experimental Groupings}

To gain further insight into subjects behavior, I construct metrics of trade, welfare, and forecasting in each grouping of analysts and shareholders and report the average over the eight-round set. The metric illuminates the joint choices of subjects in the grouping and is not dependent on rules to classify behavior. Owing to state uncertainty, each metric is the property of subjects' elicited choices and not of the random realizations displayed in the subjects summary report (see Appendix A for the construction). The metrics are shown in Table 7 .

Insert Table 7 here 


\subsection{Tests of Hypotheses}

For all hypothesis tests, I use the average response for each participant over the experiment in each role. In this way, I obtain 12 independent observations for each experiment. ${ }^{2}$ Unless stated otherwise, I perform the Wilcoxon matched-pairs signed-rank or Mann-Whitney $U$ tests on these observations.

\subsubsection{Equilibrium-Based Predictions}

Hypothesis 1 is that subjects in the conflict-of-interest treatments behave deceptively in the role of analyst and skeptically in the role of shareholder. The equilibrium prediction is that the shareholders will always trade in the low-cost experiment but never in the high-cost experiment. In the low-cost treatment, the expected benefit of trading is equal between shareholders. The average behavior reported in Table 6 (Panel A) suggests that on average, analysts were deceptive but shareholders were not skeptical. The expected trade metric shows that the average trade is similar, being lower in the low-cost treatments. Last, shareholder 1 benefited more from trade than did shareholder 2, suggesting that trade occurs at prices $\mathrm{P} 1$ and $\mathrm{P} 4$ when the state was $C$ or $D$.

In summary, it does not appear that allowing for a repeated game in the trading setting resulted in an elimination of the overcommunication phenomenon witnessed in communication games. This impression is confirmed by statistical analysis, as the $p$ value that behavior in both roles is the same is less than .01 and .04 for the low-cost and high-cost experiment, respectively.

\subsubsection{Type-Based Predictions}

Hypothesis 2 posits that subjects' behavior in the role of receiver is consistent with their own role of receiver. The average behavior reported suggests that this is not always the case. While in all experiments, there are subjects primarily honest in the role of analyst and primarily non-skeptical in the role of shareholder (albeit less in the conflict-of-interest experiments), and subjects primarily deceptive in the role of analyst and primarily skeptical in the role of shareholder, there are quite a few exceptions. In all experiments, there are subjects who are primarily deceptive in the role of analyst but primarily non-skeptical in the role of shareholder. Only in the experiments absent conflicts of interest are there subjects primarily honest in the role of analyst and primarily skeptical in the role of shareholder. As such, it does not appear that behavior measured across both roles is consistent with hypothesis 2 in the conflict-of-interest experiments. For the conflict-of-interest experiments, the $p$-value that behavior in both roles is the same is less than .01 and .04 for the low-cost and high-cost experiment, respectively.

In the absence of conflict-of-interest experiments, the average behaviors in the role of analyst and the role of shareholder are closer. While the overall difference between average behaviors shown in Table 6 is $25.0 \%$ to $31.8 \%$ in the presence of conflicts of interest, the

\footnotetext{
${ }^{2}$ Eleven for analyst behavior in the no-commission experiment.
} 
overall difference is drastically less in the absence of conflicts of interest, where the difference is $0.9 \%$ to $13.7 \%$. This impression is confirmed by statistical analysis, as the $p$-value that behavior in both roles is the same is less than .22 and .99 in the no-budget and no-commission experiment, respectively.

Can the behavior be explained by reputation formation? Examining the averages in Table 6 reveals many subjects who did not consistently use the same classified behavior. However, there are subjects who chose to be consistently honest in the role of analyst. It may be that other subjects are strategically mimicking honest analysts and later switching to deceptive strategies. In response, shareholders may be initially non-skeptical but become skeptical after witnessing deception. The sender choices are examined in each round of the set to determine if there is support for hypothesis 3. If strategic analysts are mimicking honest analysts to gain a reputation for being honest, deceptive forecasting should be lower in the first rounds of the set, when the analyst is attempting to form a reputation, and then higher in the later rounds of the set. Figure 1 shows the mean of the average deception for each player for each round. There does not appear to be a clear trend. This is statistically examined by looking at each subject's forecasting behavior in the first and last rounds of the set, testing the difference between the average in the first round and the average in the last round. Testing the null hypothesis that the behavior is the same in the first and last round of a set yields $p$-values of $.157, .063, .88$, and .94 for the high-cost, low-cost, no-budget, and no-commission experiment, respectively. ${ }^{3}$ In the high-cost experiment, the average firstround behavior is less deceptive than the average last-round behavior, albeit it is statistically insignificant at the $5 \%$ level. In the low-cost experiment, the average first-round behavior is more deceptive than the average last-round behavior but is again statistically insignificant at the $5 \%$ level.

\section{Include Figure 1 here}

Only in the high-cost experiment is there theoretical benefit to forming a reputation, resulting in hypothesis 4 that there will be more honest forecasting in the high-cost than in the low-cost experiment. While the average analyst behavior is less deceptive in the high-cost than in the low-cost experiment, this difference is only 3.0\%. Statistically, the difference is insignificant as the $p$-value of the corresponding Mann-Whitney $U$ test is .90. However, the manner of deception appears different when comparing experiments. There was over twice the proportion of exaggeration in the conflict-of-interest experiments compared to the noconflict-of-interest experiments, suggesting that the analyst most often attempted to deceive shareholders in the conflict-of-interest experiments compared to reporting haphazardly in the experiments absent conflicts of interest.

In addition to finding no support for hypotheses 3 and 4, I find no support for hypothesis 5. To test for evidence of a reaction to deceptive forecasting, I examine the average shareholder choices before and after the analyst first elects to issue a deceptive forecast in a set of eight rounds. The choices before deception include the round deception occurs as

\footnotetext{
${ }^{3}$ The test is also run comparing the first four rounds to the last four rounds of a set for each subject and yields comparable results.
} 
shareholders do not receive feedback until after their bids/asks. By construction, this metric excludes bids/asks in sets in which the analyst was honest in the first seven rounds of a set. Despite the exclusion, all shareholders experienced a deceptive forecast at least once. I test the average choices before and after encountering deceptive forecasts. The mean of the subjects' averages is shown in Figure 2 for each experiment. Only in the no-budget experiment does overall skepticism increase after the analyst used a deceptive forecast, albeit the difference is not statistically significant at the $5 \%$ level. Statistical testing uses each subject as observation. Testing the null hypothesis that the skepticism is the same before and after encountering deception yields $p$-values of $.127, .065, .41$, and .85 for the high-cost, low-cost, no-budget, and no-commission experiment, respectively.

To ensure that the classification is not failing to capture skepticism, a similar test is also run calculated using the proportion of each shareholder's bids/asks containing the prices P1 and P4. Note that this proportion is independent of any classification rule. In all experiments, the prices $\mathrm{P} 1$ and $\mathrm{P} 4$ are only consistent with the belief that the analyst is honest. In all but the high-cost treatment, the mean of the average proportions decreases, but the difference is about $1 \%$ to $2 \%$ (such as $36 \%$ of all bids down to $34 \%$ of all bids). Testing against the null hypothesis that the frequency of bids/asks containing prices P1 and $\mathrm{P} 4$ are the same before and after encountering deception yields $p$-values of $.99, .24, .23$, and .34 for the high-cost, low-cost, no-budget, and no-commission experiment, respectively.

\section{Include Figure 2 here}

In summary, I do not find support for the notion that subjects are one of two types. I do not find that behavior in each role is steadily honest/non-skeptical or deceptive/skeptical in the repeated game. Furthermore, I do not find evidence that subjects are strategically mimicking types to maximize payoffs.

\subsubsection{Levels of Strategic Reasoning Predictions}

Reviewing Table 6 for the conflict-of-interest experiments reveals that there are subjects generally honest in the role of analyst and non-skeptical in the role of shareholder, subjects generally deceptive in the role of analyst and skeptical in the role of shareholder, and generally deceptive in the role of analyst but non-skeptical in the role of shareholder. Note that there are not any subjects generally honest in the role of analyst and skeptical in the role of shareholder. This composition mirrors the types shown in Table 5a, where there is the absence of a predicted type behaving honest as an analyst and skeptical as a shareholder. To provide statistical support for hypothesis 6 , I perform a permutation test on the mean difference of the behavior in Table 6 for subjects in the conflict-of-interest experiments. The null hypothesis that behavior is the same in both roles is identical. If the null hypothesis is true, a permutation within any pair of scores is as likely as the reverse. This yields 4,096 permutations of the observed data $\left(2^{12}\right)$. The results of the test are graphed in Figures 3a and $3 \mathrm{~b}$. The one-sided $p$-values are less than .01 for both experiments, providing support for hypothesis 6 . 
Behavior is more interchangeable in the experiments absent conflicts of interest. The same aforementioned permutation tests examining the differences in behavior in the role of analyst and the role of shareholder are insignificant at the $5 \%$ significance level. The results of the test are graphed in Figures 3c and 3d. The one-sided p-values are .087 and .37 for the no-budget and no-commission experiment, respectively. ${ }^{4}$ Unlike the conflict-of-interest experiments there are subjects acting primarily honestly in the role of analyst and primarily skeptical in the role of shareholder.

\section{Insert Figure 3 here}

Hypothesis 7 posits that analysts will be more honest and shareholders more skeptical in the no-conflict-of-interest experiments. The behavior shown in Table 6 shows that the average analyst behavior is more honest in the no-conflict-of-interest experiments shown in the bottom panel than in conflict-of-interest experiments shown in the top panel, albeit the difference is slight. Shareholders appear more skeptical in the no-conflict-of-interest experiments than in the conflict-of-interest experiments. As such, there does not appear to be overwhelming support for hypothesis 7 . The interpretation is corroborated by statistical analysis showing no significant differences in behavior at the $5 \%$ level. I compare the average analyst behavior for the 24 subjects in the conflict-of-interest experiments to the 23 subjects in the no-conflict-of-interest experiments. Testing the analyst data using a Monte Carlo permutation test of 20,000 observations yields insignificance corresponding to a $p$-value of .12. Testing average shareholder behavior for the 24 subjects in the conflict-of-interest experiments to the 24 subjects in the no-conflict-of-interest experiments using a Monte Carlo permutation test of 20,000 observations also yields insignificance corresponding to a $p$-value of $.066 .{ }^{5}$ As such, I fail to find evidence for hypothesis 7 .

\section{Conclusion}

This study examines the behavior of a group of subjects with conflicts of interest in a moderately complex communication game set within a trading institution. In keeping with prior work, senders (analysts) send more information than predicted by equilibrium models assuming sequentially rational agents. Likewise, receivers (shareholders) rely on information sent more than predicted. In this work, I do not conclude that some proportion of subjects following normative social behavior explains the observed overcommunication phenomenon.

Overall, subjects' behavior is more analogous to models of limited reasoning. Though less than half the subjects chose to use honest forecasting strategies in the presence of conflicts of interest, more than half chose to use non-skeptical trading strategies. This pattern is consistent with predictions of limited strategic reasoning: when playing the role of sender,

\footnotetext{
${ }^{4}$ There are 11 paired observations in the no-commission experiment as one subject (\#44) was never randomly assigned the role of analyst. This yields 2,048 permutations.

${ }^{5}$ It was not computationally possible to test all $\frac{23 !}{12 ! 11 !}$ possible permutations of analyst behavior and all $\frac{24 !}{12 ! 12 !}$ possible permutations of shareholder behavior.
} 
a subject assumes that others are habitually non-skeptical and thus adopts a deceptive forecasting strategy. When playing the role of shareholder, the subject assumes that others are habitually honest and thus adopts a non-skeptical strategy.

The disclosure of the conflicts of interest between analysts and shareholders was not sufficient to evoke shareholder skepticism. In all experiments, shareholders do not appear to sufficiently change behavior after encountering deception in analysts' forecasts, consistent with psychological work. Taken together, the results suggest that subjects are inclined to seek out information content despite the presence of deception. Unexpectedly, disclosure of the conflicts of interest between analysts and shareholders was not sufficient to evoke shareholder skepticism. Ironically, the disclosed conflicts of interest did not appear to invoke any more skepticism than in the experiments absent conflicts of interest. The resulting reliance is similar to work by Cain et al. [2005] suggesting that disclosure of conflicts of interest might invoke images of normative or professional behavior in the eyes of shareholders and at the same time might strategically influence analysts to deceive shareholders.

Eliminating commissions might theoretically induce honesty and trust, but the experimental results suggest that this may not be the case. Though some might posit that the elimination of brokerage commissions, as the SEC barred brokerage firms from tying analysts compensation to investments in specific banking transactions, the elimination of conflicts of interest between parties may not induce honesty and trust. Despite the observed deception, eliminating brokerage commissions did increase shareholder welfare as the shareholders were more likely to capture trading gains.

\section{References}

Basu, K. 1994. The traveler's dilemma: Paradoxes of rationality in game theory. American Economic Review 84 (2): 391-395.

Blume, A., D. V. DeJong, Y.-G. Kim, and G. B. Sprinkle. 1998. Experimental evidence on the evolution of meaning of messages in sender-receiver games. American Economic Review 88 (5): 1323-1340.

Brandts, J., and G. Charness. 2000. Hot vs. cold: Sequential responses and preference stability in experimental games. Experimental Economics 2: 227-238.

Cai, H., and J. T.-Y. Wang. 2006. Overcommunication in strategic information transmission games. Games and Economic Behavior 56: 7-36.

Cain, D., G. Loewenstein, and D. A. Moore. 2005. The dirt on coming clean: Perverse effects of disclosing conflicts of interest. Journal of Legal Studies 34: 1-25.

Camerer, C. F., and K. Weigelt. 1998. Experimental tests of a sequential equilibrium reputation model. Econometrica 56 (1): 1-36. 
Camerer, C. F., T.-H. Ho, and J.-K. Chong. 2004. A cognitive hierarchy model of games. Quarterly Journal of Economics 119 (3): 861-898.

Cason, T. N., and V.-L. Mui. 1998. Social influence in the sequential dictator game. Journal of Mathematical Psychology 42: 248-265.

CIRANO. 2009. Centre for interuniversity research and analysis on organizations. December. Available at http://ecoexpaucirano.qc.ca/lab.

Crawford, V. 2003. Lying for strategic advantage: Rational and boundedly rational mispresentation of intentions. American Economic Review 93 (1): 133-149.

Crawford, V., and N. Iriberri. 2007. Fatal Attraction: Salience, naïveté, and sophistication in experimental "hide-and-seek" games. American Economic Review 97 (5): 1731-1750.

Crawford, V., and J. Sobel. 1982. Strategic information transmission. Econometrica 50 (6): 1431-1451.

Dickhaut, J., K. McCabe, and A. Mukherji. 1995. An experimental study of strategic information transmission. Economic Theory 6 (3): 389-403.

Dickhaut, J., M. Ledyard, and A. Mukherji. 2003. Information management and valuation: An experimental investigation. Games and Economic Behavior 44: 26-53.

Dickhaut, J., J. Hubbard, R. Lunawat, and K. McCabe. 2008. Trust, reciprocity, and interpersonal history: Fool me once, shame on you, fool me twice, shame on me. Mimeo. Minnesota: University of Minnesota and George Mason University.

Einhorn, H. J., and R. M. Hogarth. 1978. Confidence in judgment: Persistence of the illusion of validity. Psychological Review 85 (5): 395-416.

Fischbacher, U. 2007. Z-Tree: Zurich toolbox for ready-made economic experiments. Experimental Economics 10 (2): 171-178.

Franco, G. D., H. Lu, and F. P. Vasvari. 2007. Wealth transfer effects of analysts' misleading behavior. Journal of Accounting Research 45 (1): 71-110.

Gneezy, U. 2005. Deception: The role of consequences. American Economic Review 95 (1): $384-394$.

Greiner, B. 2004. The online recruitment system orsee 2.0-a guide for the organization of experiments in economics. Papers on Strategic Interaction 10. Max Planck Institute of Economics, Strategic Interaction Group: Munich.

Ho, T. H., C. Camerer, and K. Weigelt. 1998. Iterated dominance and iterated best response in experimental "p-beauty contests." American Economic Review 88 (4): 947-969. 
Hobson, J. L., and S. J. Kachelmeier. 2005. Strategic disclosure of risky prospects: A labortory experiment. Accounting Review 80 (3): 825-846.

Hurkens, S., and N. Kartik. 2009. Would I lie to you? On social preferences and lying aversion. Experimental Economics 12 (2): 180-192.

King, R. R., and D. E. Wallin. 1991. Voluntary disclosures when seller's level of information is unknown. Journal of Accounting Research 29 (96): 96-108.

Kreps, D., and R. Wilson. 1982. Reputation and imperfect information. Journal of Economic Theory 27 (2): 253-279.

Kreps, D., P. Milgrom, J. Roberts, and R. Wilson. 1982. Rational cooperation in the finitely repeated prisoners' dilemma. Journal of Economic Theory 27: 245-252.

Malmendier, U., and D. M. Shanthikumar. 2007. Are small investors naive about incentives? Journal of Financial Economics 85 (2): 457-489.

McKelvey, R., and T. R. Palfrey. 1992. An experimental study of the centipede game. Econometrica 60 (4): 803-836.

Michaely, R., and K. Womack. 1999. Conflict of interest and the credibility of underwriter analyst recommendations. Review of Financial Studies 12 (4): 653-686.

Nagel, R. 1995. Unraveling in guessing games: An experimental study. American Economic Review 85 (5): 1313-1326.

Oxoby, R. J., and K. N. McLeish. 2004. Sequential decision and strategy vector methods in ultimatum bargaining: Evidence on the strength of other-regarding behavior. Economic Letters 84: 399-405.

Rankin, F., S. Schwartz, and R. Young. 2008. The effect of honesty preferences and superior authority on budget proposals. Accounting Review 83 (4): 1083-1099.

Rubinstein, A. 2006. Dilemmas of an economic theorist. Econometrica 74 (4): 865-883.

Sánchez-Pagés, S., and M. Vorsatz. 2007. An experimental study of truth-telling in a senderreceiver game. Games and Economic Behavior 61 (1): 86-112.

U.S. Securities and Exchange Commission. 2008. Investor alert: Analyzing analyst recommendations. July 2. Available at http://www.sec.gov/investor/pubs/analysts.htm.

Sobel, J. 1985. A theory of credibility. Review of Economic Studies 52 (4): 557-573.

Stahl, D. I., and P. W. Wilson. 1994. Experimental evidence on players' models of other players. Jornal of Economic Behavior and Organization 25 (3): 30-327. 
Wang, J. T. Y., M. Spezio, and C. F. Camerer. Forthcoming. Pinocchio's pupil: Using eyetracking and pupil dilation to understand truth-telling and deception in games. American Economic Review.

Wilson, T. D., and N. Brekke. 1994. Mental contamination and mental correction: Unwanted influences on judgments and evaluations. Psychological Bulletin 116 (1): 117-142.

\section{A Metrics of Trade}

Metrics for trade, capturing gains to trade, and benefits of trading are constructed, rather than relying on the random realizations generated during the experiment (as described in section 3.4). These metrics are free of any stochastic noise inherent in the realizations. Parameters for the states, signals, and probabilities thereof are described in section 2.

\section{A.1 Likelihood of Trade}

The likelihood of trade is derived from subjects' input reporting and trading decisions. This metric captures to what extent subjects' input decisions prompted trade between the shareholders. This metric was defined for a round in a single economy:

$$
\left.\sum_{\text {States }} \sum_{\text {Signals }} \operatorname{Pr}(\text { state }) \operatorname{Pr}(\text { signal } \mid \text { state }) I_{f} \text { (signal }\right) .
$$

$I_{f}$ (signal) is an indicator function, defined in every round for the three subjects within a single economy. The function equals 1 if there is trade for the released message $f$ and 0 otherwise. There is trade if the input bid for the released message is greater than or equal to the input asking price for the released message. The message released is the result of the analyst's input reporting strategy for the given signal. This metric is agnostic as to the distribution of wealth and is akin to a social welfare metric.

\section{A.2 Likelihood of Shareholders Capturing Gains to Trade}

The likelihood of capturing gains to trade captures to what extent trade occurred when the state was $A$ or $D$. Not all trade benefited shareholders as a whole; rather, shareholders were only benefited by trade in states in which gains to trade exceeded trading costs. This metric is also defined in every round in a single economy, but whereas the prior metric was summed over all states, this metric is summed over states $A$ and $D$ :

$$
\sum_{\{A, D\}} \frac{\operatorname{Pr}(\text { state }) \sum_{\text {Signals }} \operatorname{Pr}(\text { signal } \mid \text { state }) I_{f}(\text { signal })}{\sum_{\{A, D\}} \operatorname{Pr}(\text { state })} .
$$




\section{A.3 Benefit of Trading}

Though trade benefited the economy as a whole, it was possible for trade to benefit one shareholder at the expense of another. The benefit of trade was calculated for each shareholder in an economy given the subjects' input reporting and trading decisions. It captures to what extent the shareholders were better electing to trade, given simply keeping their original endowments. This metric was defined for a round in a single economy and is defined separately for each shareholder:

shareholder 1

$$
\sum_{\text {States Signals }} \sum_{\operatorname{Pr}}(\text { signal } \mid \text { state }) I_{f}(\text { signal }) I_{\text {state }}\left\{T(f)-v_{1}(\text { state })+\frac{1-I_{\text {state }}}{2} \lambda\right\}
$$

shareholder 2

$$
\sum_{\text {States Signals }} \sum_{\operatorname{Pr}(\text { signal } \mid \text { state })} I_{f}(\text { signal }) I_{\text {state }}\left\{v_{2}(\text { state })-T(f)-\frac{1-I_{\text {state }}}{2} \lambda\right\} .
$$

$I_{\text {state }}$ is an indicator function capturing the direction of trade. The indicator is -1 if the state is $A$ or $B$ and 1 otherwise. $T(f)$ is the transfer price: the minimum of the input bid and input ask for the released report $f$. Both $v_{1}($.$) and v_{2}($.$) are the payoffs to shareholder 1$ and 2 , respectively, given the state. The payoffs and the costs of trading, $\lambda$, are experiment parameters described in section 2 .

\section{B Tables and Figures}


Table 1: Experimental Parameters for Conflict-of-Interest Experiments

(a) Shareholder State-Based Payoffs ${ }^{\mathrm{a}}$

\begin{tabular}{lcccc}
\hline State & $A$ & $B$ & $C$ & $D$ \\
\hline Payoff to shareholder 1 & 30 & 50 & 70 & 90 \\
Payoff to shareholder 2 & 0 & 40 & 80 & 120 \\
Difference & 30 & 10 & 10 & 30 \\
\hline
\end{tabular}

(b) Chances of State Given Analyst's Private Signal ${ }^{\mathrm{b}}$

\begin{tabular}{lllll}
\hline Signal observed & $\tilde{A}$ & $\tilde{B}$ & $\tilde{C}$ & $\tilde{D}$ \\
\hline Probability state $A$ & .9 & .1 & & \\
Probability state $B$ & .1 & .9 & & \\
Probability state $C$ & & & .9 & .1 \\
Probability state $D$ & & & .1 & .9 \\
\hline
\end{tabular}

(c) Shareholder's Net Gains to Trading ${ }^{c}$

\begin{tabular}{lcccc}
\hline State & $A$ & $B$ & $C$ & $D$ \\
\hline Net gains in low-cost experiment & 17 & -3 & -3 & 17 \\
Net gains in high-cost experiment & 9 & -11 & -11 & 9 \\
\hline
\end{tabular}

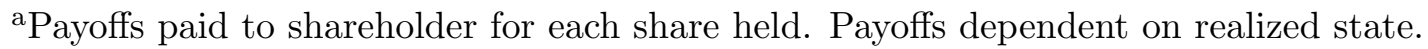

bAnalyst's signal structure governing imprecise analyst information.

${ }^{\mathrm{c}}$ Ex post net gains after subtracting trading costs of 13 lira and 21 lira in the low-cost and high-cost experiments respectively. 
Table 2: Experimental Parameters for No-Conflict-of-Interest Experiments

(a) Shareholder State-Based Payoffs For No-Budget Experiment ${ }^{\mathrm{a}}$

\begin{tabular}{lcccc}
\hline State & $A$ & $B$ & $C$ & $D$ \\
\hline Payoff to shareholder 1 & 30 & 50 & 70 & 90 \\
Payoff to shareholder 2 & 0 & 40 & 80 & 120 \\
Difference & 30 & 10 & 10 & 30 \\
\hline
\end{tabular}

(b) Shareholder State-Based Payoffs For No-Commission Experiment ${ }^{\mathrm{a}}$

\begin{tabular}{lcccc}
\hline State & $A$ & $B$ & $C$ & $D$ \\
\hline Payoff to shareholder 1 & 26 & 46 & 70 & 90 \\
Payoff to shareholder 2 & 0 & 40 & 76 & 116 \\
Difference & 26 & 6 & 6 & 26 \\
\hline
\end{tabular}

(c) Chances of State Given Analyst's Private Signal ${ }^{\mathrm{b}}$

\begin{tabular}{lllll}
\hline Signal observed & $\tilde{A}$ & $\tilde{B}$ & $\tilde{C}$ & $\tilde{D}$ \\
\hline Probability state $A$ & .9 & .1 & & \\
Probability state $B$ & .1 & .9 & & \\
Probability state $C$ & & & .9 & .1 \\
Probability state $D$ & & & .1 & .9 \\
\hline
\end{tabular}

(d) Shareholder's Gains to Tradingc

\begin{tabular}{lcccc}
\hline State & $A$ & $B$ & $C$ & $D$ \\
\hline Difference in payoffs for no-budget experiment $^{(i)}$ & 30 & 10 & 10 & 30 \\
Difference in payoffs for no-commission experiment $^{(i i)}$ & 26 & 6 & 6 & 26 \\
Net gains to trading (for both experiments) $^{\text {Net }}$ & 17 & -3 & -3 & 17 \\
\hline
\end{tabular}

aPayoffs paid to shareholder for each share held. Payoffs dependent on realized state.

bAnalyst's signal structure governing imprecise analyst information.

${ }^{\mathrm{c}}$ Trading costs paid by the buyer are subtracted from difference in payoffs to arrive at gains to trading. Trading costs are (i) 13 lira and (ii) 9 lira in the no-budget and no-commission experiments, respectively. 


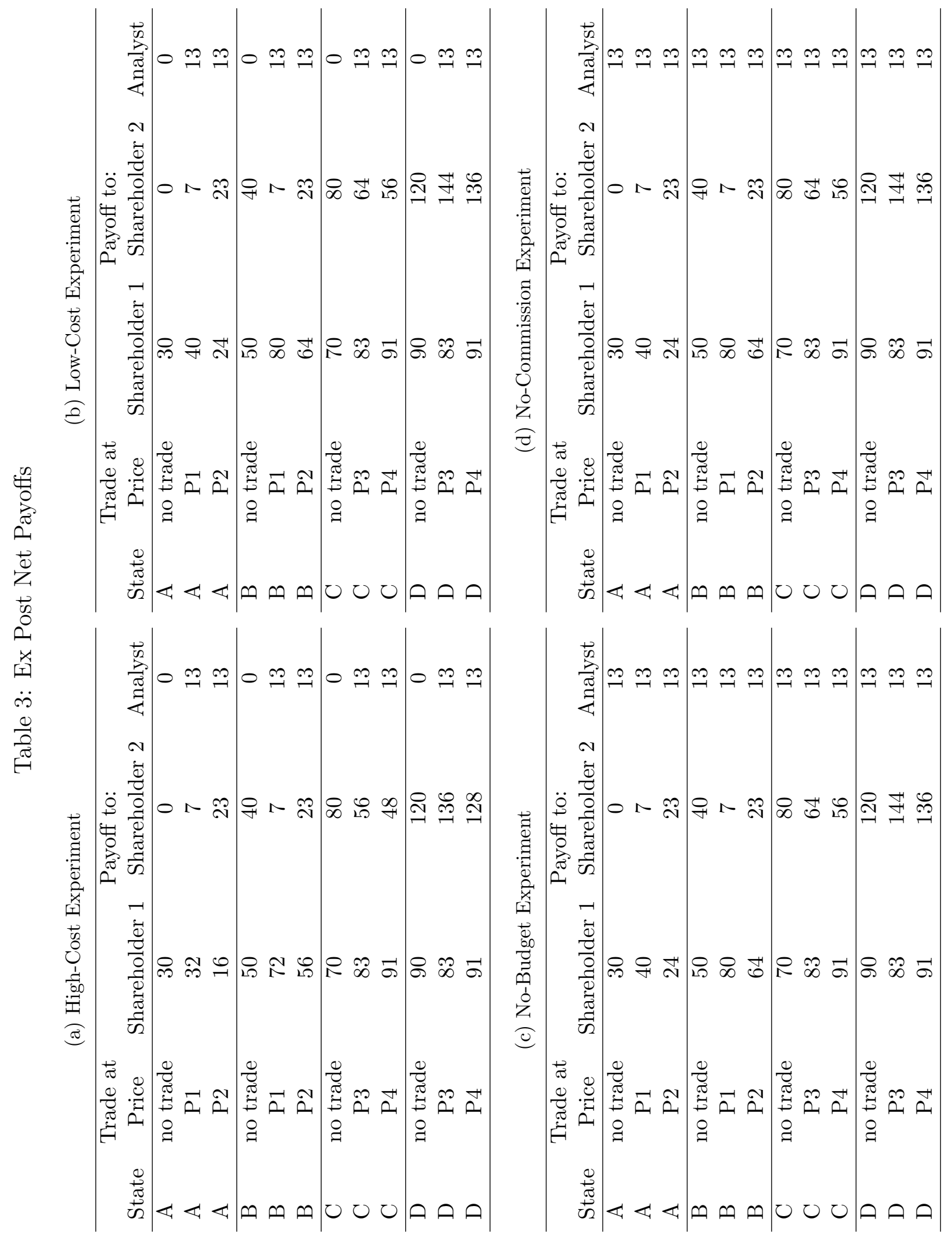


Table 4: Shareholders' Expected Payoffs

(a) Assuming Honest Forecasting

\begin{tabular}{lcccc}
\hline Forecast & $\hat{A}$ & $\hat{B}$ & $\hat{D}$ & $\hat{D}$ \\
\hline Expected payoff to shareholder 1 & 32 & 48 & 72 & 88 \\
Expected payoff to shareholder 2 & 4 & 36 & 84 & 116 \\
Difference & 28 & 12 & 12 & 28 \\
\hline
\end{tabular}

(b) Assuming Deceptive Forecasting

\begin{tabular}{lcc}
\hline Forecast & $\hat{A}$ or $\hat{B}$ & $\hat{C}$ or $\hat{D}$ \\
\hline Expected payoff to shareholder 1 & 40 & 80 \\
Expected payoff to shareholder 2 & 20 & 100 \\
Difference & 20 & 20 \\
\hline
\end{tabular}

The shareholders' expected payoff given the imprecision in the analysts private information assuming that the analyst is honestly revealing her private information or adopting deceptive forecasting. 
Table 5: Types in Levels of Reasoning Framework

(a) In the Presence of Conflicts of Interest

\begin{tabular}{lcc}
\hline Type & Behavior as analyst & Behavior as shareholder \\
\hline Level-0 & honest & non-skeptical \\
Level-1 & deceptive & non-skeptical \\
Level-2 & deceptive & skeptical \\
\hline
\end{tabular}

(b) In the Absence of Conflicts of Interest

\begin{tabular}{lcc}
\hline Type & Behavior as analyst & Behavior as shareholder \\
\hline Level-0 & honest & non-skeptical \\
Level-1 & honest or deceptive & non-skeptical \\
Level-2 & honest or deceptive & skeptical \\
\hline
\end{tabular}

Predictions based on differing levels of strategic reasoning are constructed on a nonstrategic base-level strategy. Each subsequent level of the hierarchy is defined as the best response assuming that other players use a lower level of strategic reasoning. 


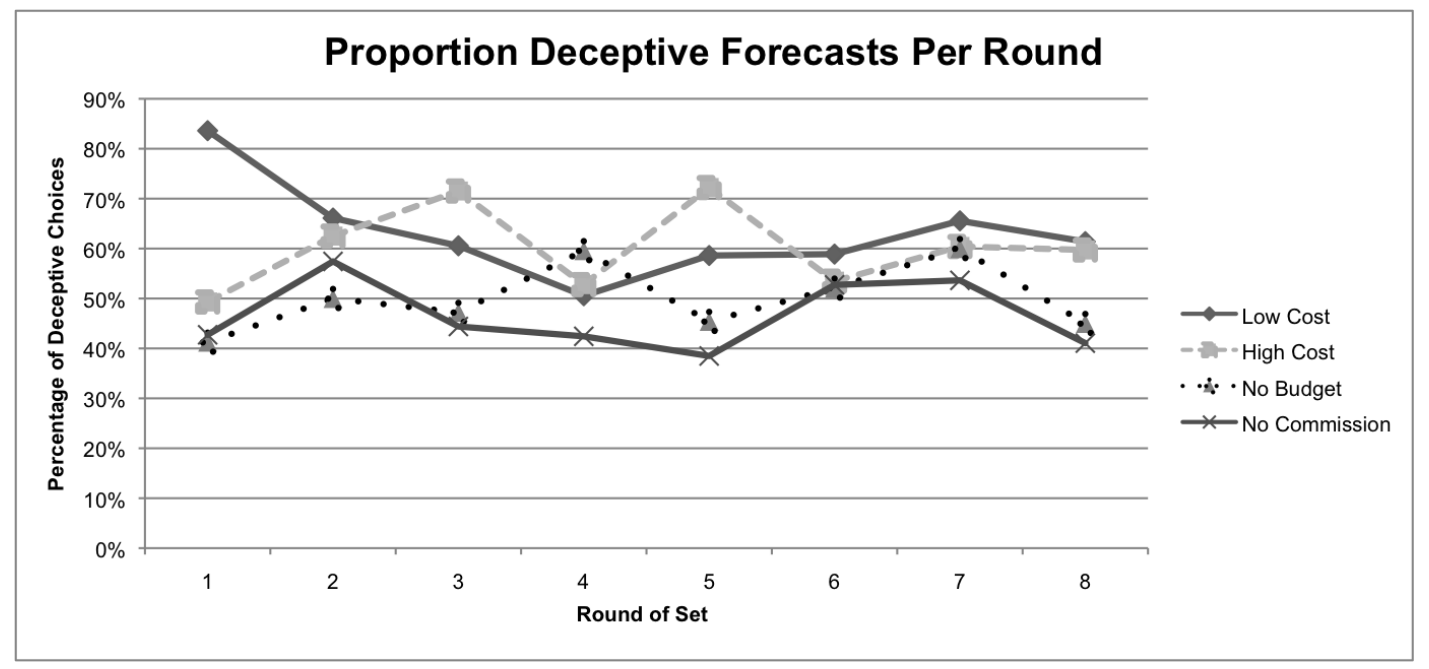

Figure 1: Proportion of deceptive forecasts per round.

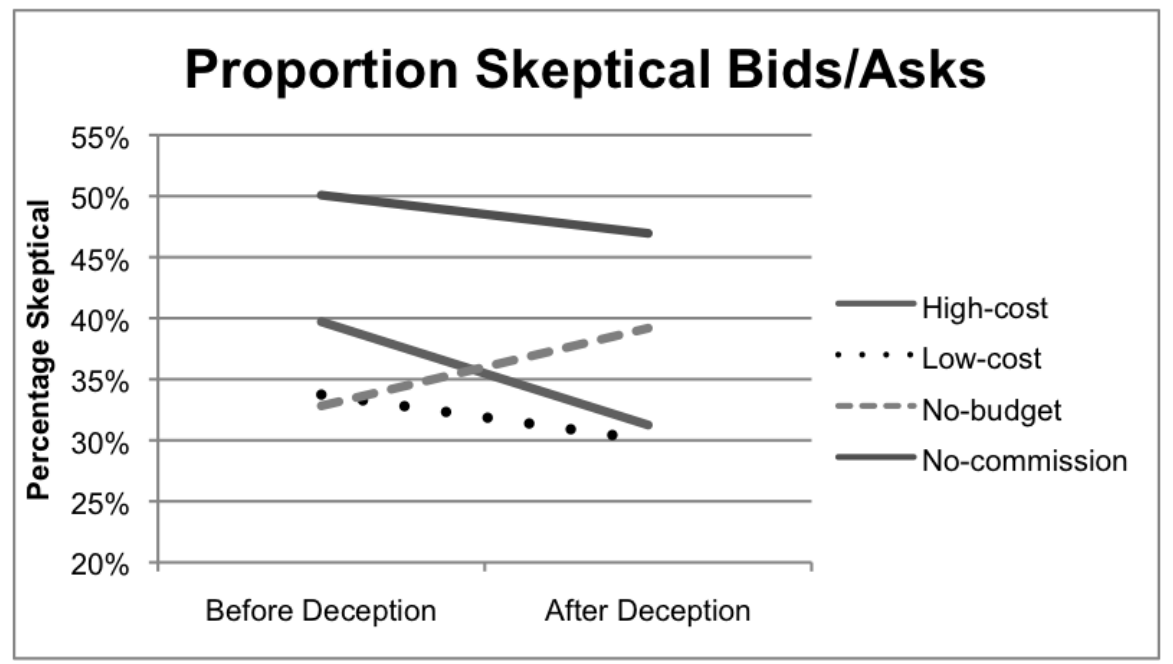

Figure 2: Proportion of skeptical bids/asks. 
Table 6: Overall Behavior in All Experiments

\begin{tabular}{|c|c|c|c|c|c|}
\hline \multicolumn{3}{|c|}{ High-cost experiment } & \multicolumn{3}{|c|}{ Low-cost experiment } \\
\hline Subject & Deceptive $^{\mathrm{a}}(\%)$ & Skeptical $^{\mathrm{a}}(\%)$ & Subject & Deceptive $^{\mathrm{a}}(\%)$ & Skeptical $^{\mathrm{a}}(\%)$ \\
\hline$\# 1$ & 50.0 & 35.4 & \#13 & 66.7 & 27.5 \\
\hline \#2 & 91.7 & 25.0 & \#14 & 62.5 & 14.6 \\
\hline \#3 & 56.3 & 31.3 & \#15 & 81.3 & 45.8 \\
\hline \#4 & 70.8 & 50.0 & \#16 & 100.0 & 42.5 \\
\hline \#5 & 0.0 & 16.7 & \#17 & 75.0 & 46.4 \\
\hline \#6 & 91.7 & 60.0 & \#18 & 87.5 & 42.9 \\
\hline$\# 7$ & 93.8 & 35.4 & \#19 & 50.0 & 22.9 \\
\hline \#8 & 87.5 & 37.5 & \#20 & 68.8 & 62.5 \\
\hline \#9 & 12.5 & 41.1 & \#21 & 35.0 & 16.7 \\
\hline \#10 & 100.0 & 15.6 & \#22 & 56.3 & 12.5 \\
\hline \#11 & 18.8 & 25.0 & \#23 & 41.7 & 30.0 \\
\hline \#12 & 50.0 & 50.0 & \#24 & 33.3 & 12.5 \\
\hline Average & 60.2 & 35.2 & & 63.2 & 31.4 \\
\hline
\end{tabular}

Panel A: Conflict-of-interest experiments

\begin{tabular}{rccrcc}
\hline & \multicolumn{2}{c}{ No-budget experiment $^{\text {Budget-balance experiment }}$} \\
Subject & Deceptive $^{\mathrm{a}}(\%)$ & Skeptical $^{\mathrm{a}}(\%)$ & Subject $^{\text {Deceptive }}$ & (\%) & Skeptical $^{\mathrm{a}}(\%)$ \\
\hline$\# 25$ & 100.0 & 33.9 & $\# 37$ & 0.0 & 42.9 \\
$\# 26$ & 75.0 & 6.3 & $\# 38$ & 84.4 & 71.9 \\
$\# 27$ & 0.0 & 16.1 & $\# 39$ & 83.3 & 77.5 \\
$\# 28$ & 93.8 & 70.8 & $\# 40$ & 93.8 & 18.8 \\
$\# 29$ & 20.0 & 41.7 & $\# 41$ & 37.5 & 67.5 \\
$\# 30$ & 0.0 & 3.1 & $\# 42$ & 0.0 & 53.6 \\
$\# 31$ & 85.0 & 45.8 & $\# 43$ & 25.0 & 45.8 \\
$\# 32$ & 37.5 & 60.7 & $\# 44$ & NA & 71.9 \\
$\# 33$ & 50.0 & 33.3 & $\# 45$ & 56.3 & 47.9 \\
$\# 34$ & 0.0 & 20.8 & $\# 46$ & 22.5 & 4.2 \\
$\# 35$ & 43.8 & 33.3 & $\# 47$ & 75.0 & 47.9 \\
$\# 36$ & 95.8 & 70.0 & $\# 48$ & 35.0 & 20.8 \\
\hline Average & 50.1 & 36.3 & & 46.6 & 47.5 \\
\hline
\end{tabular}

Panel B: No conflict-of-interest experiments

a Percentage of time subject used deceptive forecasting and skeptical trading decisions. 


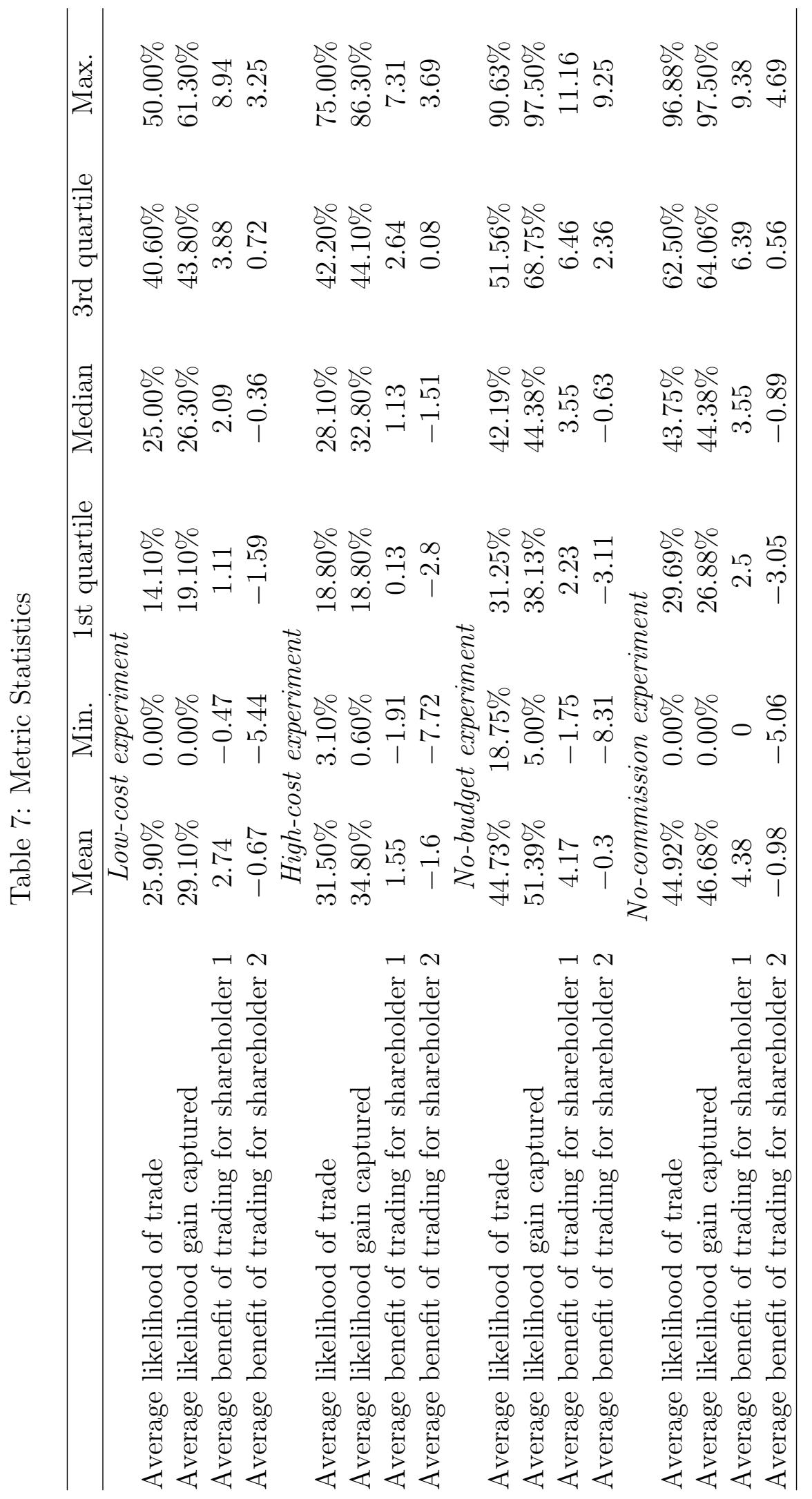


Figure 3: Difference of the Means

(a) High-cost experiment

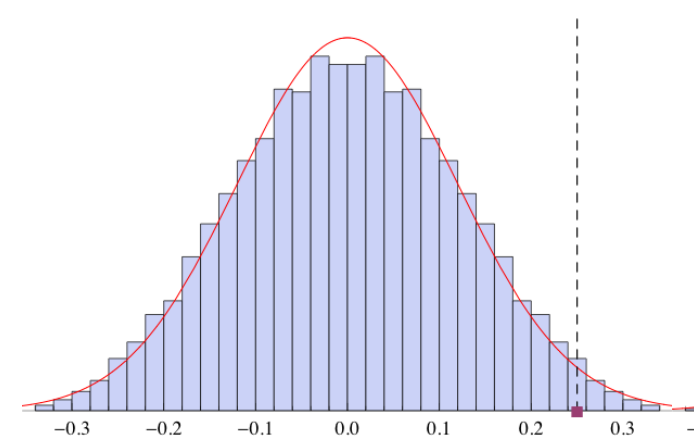

(c) No-budget experiment (b) Low-cost experiment

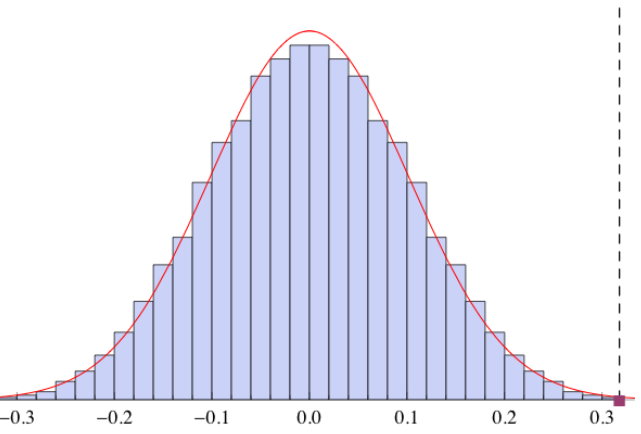

(d) No-commission experiment

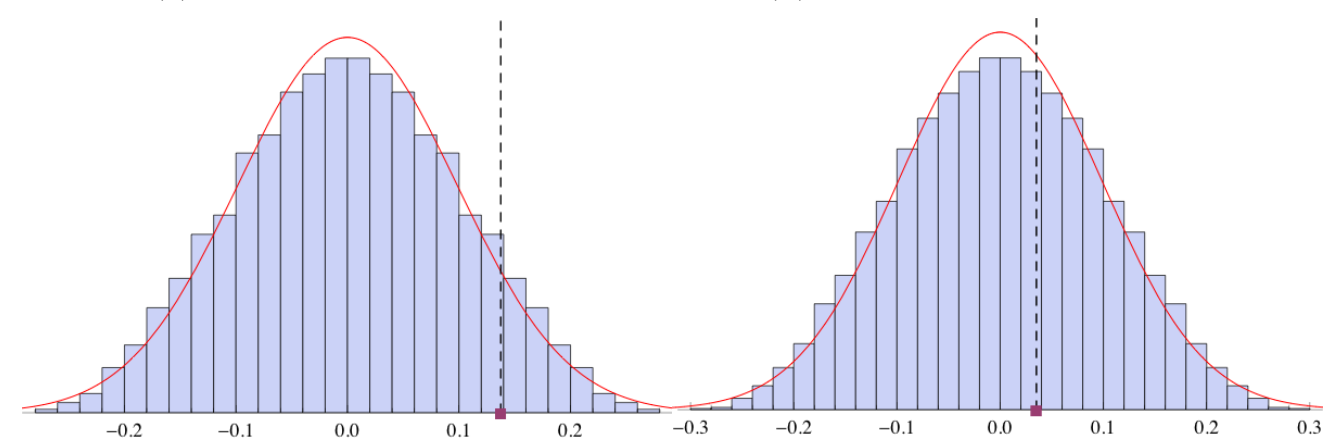

The distribution for mean difference for the permutations formed using the paired data in Table 6 for each experiment. The dashed line denotes the observed difference between behavior in the role of analyst and shareholder and the bell curve the normal distribution using the permutation's average and variance. 


\section{Economic Science Institute Working Papers}

2010

10-04 Lin, S. and Rassenti, S. Are Under- and Over-reaction the Same Matter? A Price Inertia based Account.

10-03 Lin, S. Gradual Information Diffusion and Asset Price Momentum.

10-02 Gjerstad, S. and Smith, V. Household expenditure cycles and economic cycles, 1920 - 2010.

10-01 Dickhaut, J., Lin, S., Porter, D. and Smith, V. Durability, Re-trading and Market Performance.

2009

09-11 Hazlett, T., Porter, D., Smith, V. Radio Spectrum and the Disruptive Clarity OF Ronald Coase.

09-10 Sheremeta, R. Expenditures and Information Disclosure in Two-Stage Political Contests.

09-09 Sheremeta, R. and Zhang, J. Can Groups Solve the Problem of Over-Bidding in Contests?

09-08 Sheremeta, R. and Zhang, J. Multi-Level Trust Game with "Insider" Communication.

09-07 Price, C. and Sheremeta, R. Endowment Effects in Contests.

09-06 Cason, T., Savikhin, A. and Sheremeta, R. Cooperation Spillovers in Coordination Games.

09-05 Sheremeta, R. Contest Design: An Experimental Investigation.

09-04 Sheremeta, R. Experimental Comparison of Multi-Stage and One-Stage Contests.

09-03 Smith, A., Skarbek, D., and Wilson, B. Anarchy, Groups, and Conflict: An Experiment on the Emergence of Protective Associations.

09-02 Jaworski, T. and Wilson, B. Go West Young Man: Self-selection and Endogenous Property Rights.

09-01 Gjerstad, S. Housing Market Price Tier Movements in an Expansion and Collapse.

2008

08-10 Dickhaut, J., Houser, D., Aimone, J., Tila, D. and Johnson, C. Payoffs: Inducing Preferences with Holt-Laury Gambles.

08-09 Stecher, J., Shields, T. and Dickhaut, J. Generating Ambiguity in the Laboratory.

08-08 Stecher, J., Lunawat, R., Pronin, K. and Dickhaut, J. Decision Making and Trade without Probabilities. 
08-07 Dickhaut, J., Lungu, O., Smith, V., Xin, B. and Rustichini, A. A Neuronal Mechanism of Choice.

08-06 Anctil, R., Dickhaut, J., Johnson, K., and Kanodia, C. Does Information Transparency Decrease Coordination Failure?

08-05 Tila, D. and Porter, D. Group Prediction in Information Markets With and Without Trading Information and Price Manipulation Incentives.

08-04 Caginalp, G., Hao, L., Porter, D. and Smith, V. Asset Market Reactions to News: An Experimental Study.

08-03 Thomas, C. and Wilson, B. Horizontal Product Differentiation in Auctions and Multilateral Negotiations.

08-02 Oprea, R., Wilson, B. and Zillante, A. War of Attrition: Evidence from a Laboratory Experiment on Market Exit.

08-01 Oprea, R., Porter, D., Hibbert, C., Hanson, R. and Tila, D. Can Manipulators Mislead Prediction Market Observers? 